ARTICLE OPEN

\title{
The draining of capillary liquids from containers with interior corners aboard the ISS
}

\author{
Joshua McCraney ${ }^{1 凶}$, Mark Weislogel ${ }^{2}$ and Paul Steen ${ }^{3}$
}

In this work, we analyze liquid drains from containers in effective zero-g conditions aboard the International Space Station (ISS). The efficient draining of capillary fluids from conduits, containers, and media is critical in particular to high-value liquid samples such as minuscule biofluidics processing on earth and enormous cryogenic fuels management aboard spacecraft. The amount and rate of liquid drained can be of key concern. In the absence of strong gravitational effects, system geometry, and liquid wetting dominate capillary fluidic behavior. During the years 2010-2015, NASA conducted a series of handheld experiments aboard the ISS to observe "large" length scale capillary fluidic phenomena in a variety of irregular containers with interior corners. In this work, we focus on particular single exit port draining flows from such containers and digitize hours of archived NASA video records to quantify transient interface profiles and volumetric flow rates. These data are immediately useful for theoretical and numerical model benchmarks. We demonstrate this by making comparisons to lubrication models for slender flows in simplified geometries which show variable agreement with the data, in part validating certain geometry-dependent dynamical interface curvature boundary conditions while invalidating others. We further compare the data for the draining of complex vane networks and identify the limits of the current theory. All analyzed data is made available to the public as MATLAB files, as detailed within.

npj Microgravity (2021)7:45; https://doi.org/10.1038/s41526-021-00173-5

\section{INTRODUCTION}

On earth, a hole in the bottom of a liquid-filled bucket is a convenient way to drain it. However, in the nearly weightless environment of orbiting or coast spacecraft, there is no "bottom" because there is effectively no gravity, and the liquid simply remains in the bucket. In fact, for many liquid handling operations aboard spacecraft, the phenomena are dominated by passive capillary forces over large length scales to which we are not accustomed. However, it is no less necessary to drain "buckets" aboard spacecraft; i.e., fuels, propellants, coolants, water. In terrestrial systems the effects of capillary forces have long been observed and exploited for sub-millimetric/micro-liter scale fluids processes where capillary forces are similarly dominant, including capillary origami ${ }^{1}$, bioprinting via elastic gels ${ }^{2}$, and lab-on-chip processes ${ }^{3,4}$. Especially in situations where the liquid involved is precious, it is important to process it in a manner that wastes nothing; i.e., one that achieves maximum drain rates with minimum liquid hold-up as a function of initial conditions, container geometry, and fluid properties.

In this paper we investigate the single port capillary draining of containers with interior corners, the interior corner serving as an open capillary conduit through which the liquid may be efficiently removed. Applications on earth and aboard spacecraft abound provided the flows are capillary-dominated as measured by the Bond number

$$
\text { Bo } \equiv \frac{\Delta \rho g H^{2}}{\sigma}<1
$$

where $\Delta \rho$ is the density difference across the interface, $g$ the local acceleration field strength (i.e., gravity), $H$ the characteristic length or height of the liquid along the interior corner, and $\sigma$ the surface tension. Bo $<1$ is readily achieved aboard spacecraft where $g$ $\sim 10^{-6} g_{o}$ is common. In low-gravity environments, the interior corner provides a measure of fluid stability ${ }^{5}$, say from residual accelerations, crew docking, and orbital maneuvers. In such cases $H$ becomes the capillary length scale for the problem.

The Concus-Finn wetting condition ${ }^{6}$, which dictates the critical wetting conditions for a capillary flow to advance or recede depending on flow properties and corner geometry, specifies when a corner imbibes a liquid. While this work was mathematical, earlier heuristic critical wetting studies include bubble growth wetting $^{7}$, meniscus stability in nucleation ${ }^{8}$, and drop condensation ${ }^{9}$. Through these works, tight arguments for idealized flow scenarios simplify the governing equations of motion to lubrication equations in corner flows ${ }^{10,11}$. Capillary corner flows have gained recent attention due to their prevalence aboard spacecraft for low-g liquid containment devices and have such been studied in myriad geometries including flows in propellant tank vane networks ${ }^{12}$, flow stability ${ }^{13}$, curved corners ${ }^{14}$, open rectangular channels $^{15}$, and theoretical ${ }^{16}$ and experimental ${ }^{17,18}$ flows along nonplanar corners. Examples of short-duration low-g numerical investigations include single interior corners ${ }^{19}$, square channels ${ }^{20}$, stepped corners $^{21}$, rounded corner walls ${ }^{22}$, and rounded vertices $^{23,24}$. These investigations assume local parallel flow with negligible streamwise curvature and inertia as highlighted in earlier developments ${ }^{25-27}$. For example flows with non-negligible streamwise curvature and inertia we refer the reader elsewhere ${ }^{28}$.

For the typical liquids of terrestrial applications the critical length scale is the capillary length scale $H \sim(\sigma / \rho g)^{1 / 2}$, which is submillimetric. However, in microgravity environments $H$ can achieve sub-metric levels. The latter produces capillary flows and phenomena at unearthly large length scales with viscouscapillary time scales and inertial-capillary balances orders of magnitude above what is encountered on earth. As a

\footnotetext{
${ }^{1}$ Sibley School of Mechanical and Aerospace Engineering, Cornell University, Ithaca, NY 14850, United States. ${ }^{2}$ Department of Mechanical and Materials Engineering, Portland State University, Portland, OR 97201, United States. ${ }^{3}$ Smith School of Chemical and Biomolecular Engineering, Cornell University, Ithaca, NY 14850, United States.

更email: jm2555@cornell.edu
} 
consequence, due to the rarity of access to space, efforts are wellspent to extract as much quantitative data as possible from observed microgravity fluid behavior, a tack we pursue in this work.

In this paper we briefly review the story of NASA's Capillary Flow Experiments conducted on the International Space Station over a 5-year period between 2010-2015. We sort through the many macro-capillary fluidic experiments performed, digitizing those experiments that provide fundamental flow data of relevance to the draining of precious liquids in containers with interior corners through single port locations. The work is plodding with each of the seven container types quantified in order. The data is useful for theoretical and numerical benchmarking, which we demonstrate using an established lubrication model. Good, adequate, and poor agreement in such comparisons provides directions for model acceptance or improvements, especially as regards the novelty of such low-g capillary flows with their centimetric viscous length scales and unusually high inertia.

\section{METHODS}

\section{Single drain experiments and data reduction}

The capillary flow experiments (CFE) conducted aboard the International Space Station (ISS) by NASA were a series of handheld, centimetric-scale liquid experiments designed to probe capillary phenomena of fundamental and applied importance including contact line dynamics (CFE-CL, Contact Line), critical wetting in discontinuous structures (CFE-VG, Vane Gap), and passive ullage migration and bubble separations (CFE-ICF, Interior Corner Flow $)^{29,30}$. Following completion of the experiments in flight, a NASA video archive for CFE was made publicly available at https://psi.nasa.gov/. The low-g flight data we analyse herein is mined from this resource.

In short, each CFE experiment required the partial filling of a certain container with liquid, observing the response of the liquid in low-g, and then simply draining that same liquid from the container. Approximately 2 to $3 \mathrm{~h}$ of crew time were required for each operation which included time to retrieve, set up, operate, and stow the hardware. Due to the rarity of observing such phenomena, even the filling and draining of such containers can be viewed as of both fundamental and applied interest. The CFE experiments were not designed with a quantitative study of capillary draining flows in mind. However, since such draining events were conducted as part of other procedures, their valued incidental nature is offset by their more qualitative character due to, say, manually-controlled drain rates as will be described.

We are interested in the capillary draining of containers with interior corners from a single exit port. Fig. 1 provides an image, solid model, and wire model for a typical drain test for CFE-ICF-1, for example. The breadth of the CFE-ICF experiment geometries is depicted using wire models in Fig. 2. Of the nine ICF experiments conducted (ICF-1, ICF-2, ..., ICF-9), seven single drain tests a

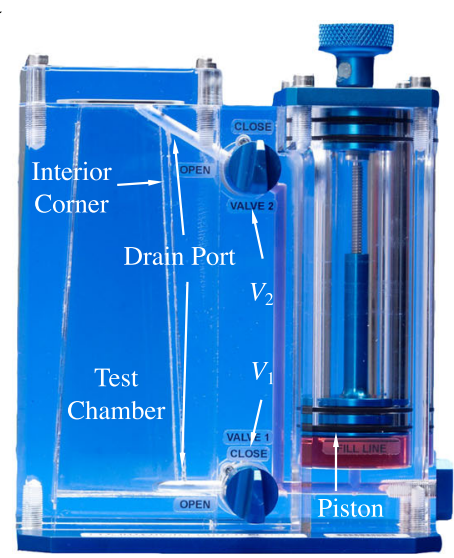

b

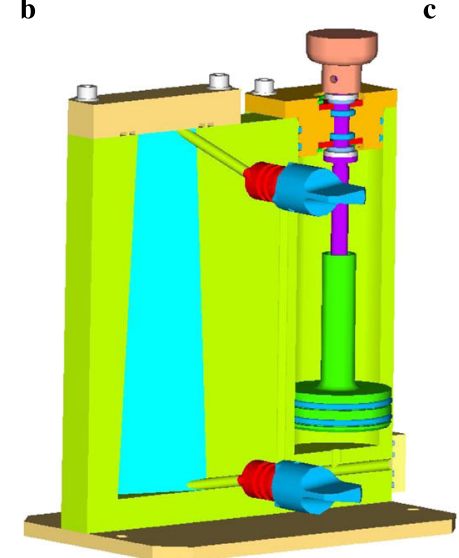

c

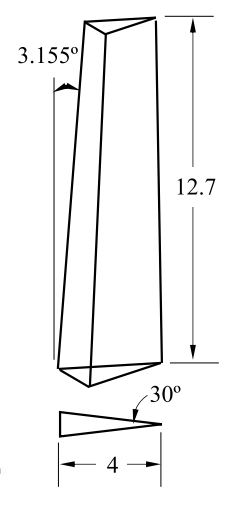

d

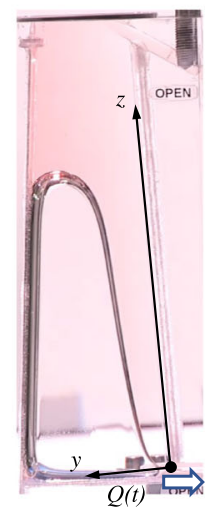

Fig. 1 Annotated ICF-1 test vessel. Slender truncated 75-30-75 isosceles triangle-based pyramid with $3.155^{\circ}$ taper. a Camera view of apparatus with valves $V_{1}$ and $V_{2}$ labeled, $\mathbf{b}$ solid model, $\mathbf{c}$ tapered test chamber wire model with dimensions in $\mathrm{cm}$, where large-end (bottom) to small-end (top) cross-sectional isosceles triangles are congruent through a 20:13 ratio, and $\mathbf{d}$ cropped image of test chamber single drain operation aboard ISS. In addition to a superposition of the relevant coordinate system, $\mathbf{d}$ provides a bold blue arrow indicating drain direction at flow rate $Q(t)$.
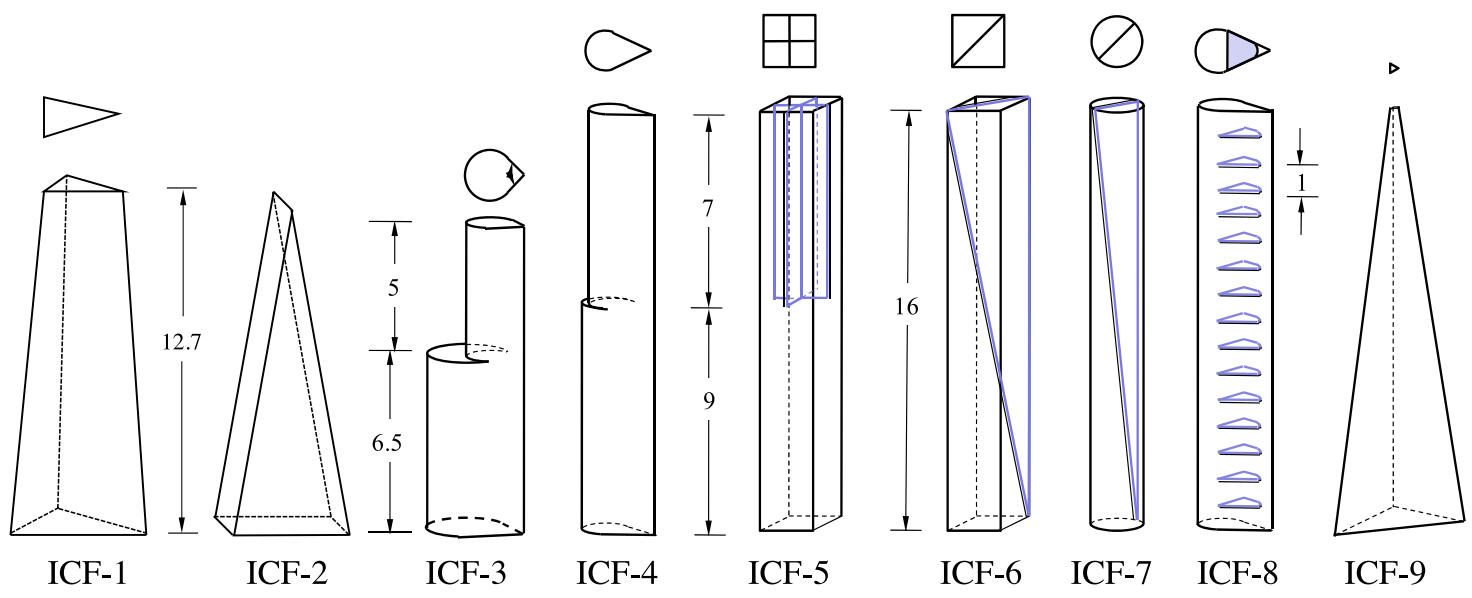

Fig. 2 ICF test cells. Wire model sketches of ICF test cells with dimensions in $\mathrm{cm}$. 
$\mathbf{a}$

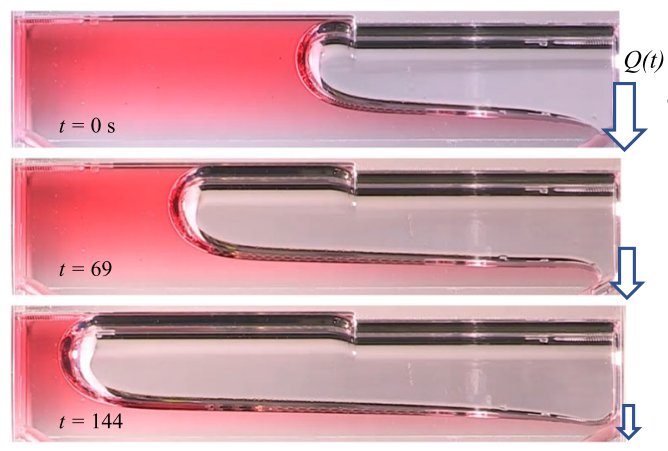

$\mathbf{b}$

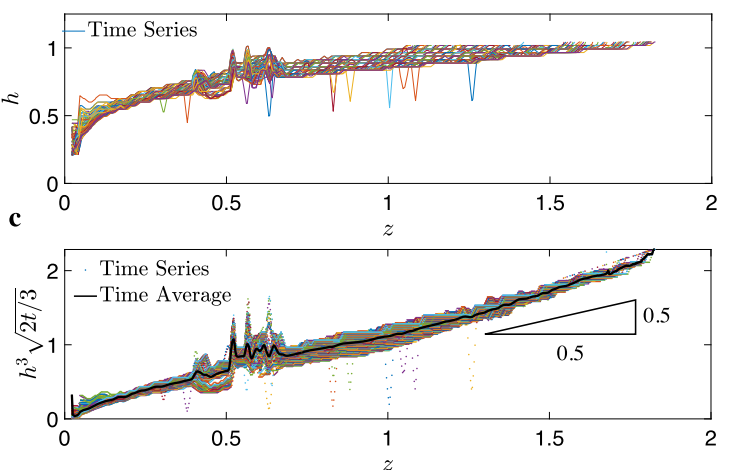

Fig. 3 ICF single drain flow. a Time sequence of perfectly wetting $\theta=0^{\circ}$ red-dyed 2 cs PDMS in the ICF- 4 test chamber drained through the "small-end" exit port at right. Note that the top image shows the ideal interface position at the drain port, the middle image shows gas ingestion, and the lower image shows an under-drained condition. $\mathbf{b}, \mathbf{c}$ Dimensionless corner flow interface height profile $h(z, t)$ for small-end drain tests for the ICF-4 test cell: $\mathbf{b} h(z, t)$ and $\mathbf{c} h^{3}(2 t / 3)^{1 / 2}$ self-similar lubrication model solution with right triangle depicting slope of unity despite unequally scaled axes. The arbitrarily colored lines in $\mathbf{b}$ and dots in $\mathbf{c}$ are incremented at $1 \mathrm{~Hz}$ for the full $128 \mathrm{~s}$ run. In $\mathbf{b}$ the $h(z, t)$ profiles decrease and extend with time, whereas in c they scatter about the time-averaged value (black line).

underwent single draining, and all are analysed and reported in detail herein. The results provide benchmarks for analytical and numerical methods predicting liquid drain rates and drain amounts from increasingly complex containers in low-g environments. All ICF tests employ perfectly wetting PDMS test fluids of select viscosity. (Note: Single drain tests imply the capillary draining of interior corners from one location, as opposed to doubly-drained interior corner tests which effectively employ two drain locations ${ }^{31}$. We also note that a single drain location often drains liquid through more than one interconnected interior corner).

As our first test case, Fig. 1 provides an annotated image, solid model, and wire model sketch for the ICF-1 test vessel-a slender truncated 75-30-75 isosceles triangle-based pyramid. The test cell was originally designed for low distortion imaging of the flow along the $30^{\circ}$ interior corner. For a partially filled vessel, the taper of the container provides a passive means of bubble migration and separation. A brief review of the drain procedures from a typical ICF vessel is as follows: The vessel was placed on an ISS work bench (MWA), back-lit by a diffuse light screen via cabin and portable lighting, and filmed via an HD Canon XF305 video camcorder. The test vessel was partially filled with liquid achieving a global low-g static equilibrium configuration. The astronaut then opened valve $V_{1}$ or $V_{2}$, often accessing the primary acute interior corner of the vessel, and drained the liquid into the reservoir by manually turning the piston dial counterclockwise. The dial was turned as quickly and continuously as possible trying not to ingest air at the drain port. Thus, a transient "maximum" drain rate from the test cell was established.

Figure 3a provides images during the drain process for the ICF-4 test vessel. For this effectively constant cross-sectional area test cell drain scenario, as the liquid is removed, the bulk meniscus recedes, the interior corner flow length increases, and the overall maximum drain rate decreases. The capillary corner flow is driven by the capillary pressure gradient created at the exit port drain location. The astronaut works to drain the liquid as quickly as possible, establishing a nearly zero height meniscus at the drain location without ingesting gas. Transient fluid interface profile histories may be determined from such images. An annotated sketch of the flow modeled after ICF-4 is provided in Fig. 4 with profile and sectional views. The container geometry, fluid properties, and initial fill volume serve as the independent variables of the tests. The corner flow drain rates for ICF- $1,-2,-3,-4,-6,-8$, and -9 vessels are documented herein.
The ISS CFE-ICF drain test video data on the NASA archive is digitally reduced and analyzed herein, yielding time-dependent interface profiles, bulk meniscus receding velocities, and volumetric drain rates. As will be discussed in connection with the sketch of Fig. 4, the primary objectives are to digitize the fluid interface for the receding bulk meniscus $z_{2}(t)$ and interior corner height profiles $h(z, t)$, while tracking time-dependent piston position to extract integral volumetric flow rates $Q(t)$. For the data reduction, we employ in-house developed automated interface tracking algorithms to digitize the interface positions ${ }^{32}$. In brief, we first convert the video to low-loss still images and then reduce them to binary files. As indicated in Supplementary Fig. 1a for ICF4 , to reduce image noise due in part to small sparse air bubbles and spurious reflections, we apply a Canny filter ${ }^{33}$ applying two thresholds for edge detection sensitivity. We then increment the region of interest for each image and tabulate the desired interface pixels. This process is performed many hundreds of times for a total of 8442 seconds of low-g drain data over thousands of pixels for each still frame. The intermediate interfaces detected are then passed through a moving-average filter establishing the smoothed meniscus profiles $h(z, t)$ traced, for example, $h(z, t)$ in Supplementary Fig. $1 \mathrm{~b}$ for ICF-3 (green line profile). As observed in Supplementary Fig. 1a, the presence of bubbles can pose challenges to the automated scheme, requiring either further filtering or manual tracking to determine $h(z, t)$.

The HD video camcorder and ICF test vessel are manually positioned on the ISS work bench. Our digitized data are subsequently corrected for optical distortions arising from any misalignment and distortions caused by mismatched indices of refraction. The former could be shown to be truly negligible due to the $\sim 1 \mathrm{~m}$ working distance of the camera, but ray trace analyses of the latter identified interface position corrections from $2 \%$ to nearly $10 \%$. As a result, all ICF data sets are corrected for distortion due to diffraction.

\section{Reporting Summary}

Further information on research design is available in the Nature Research Reporting Summary linked to this article.

\section{RESULTS}

\section{Lubrication theory overview}

A current prediction of capillary draining from containers with interior corners exploits the lubrication approximation for slender flows $^{34}$. We summarize the key details of the theory for 
$\mathbf{a}$

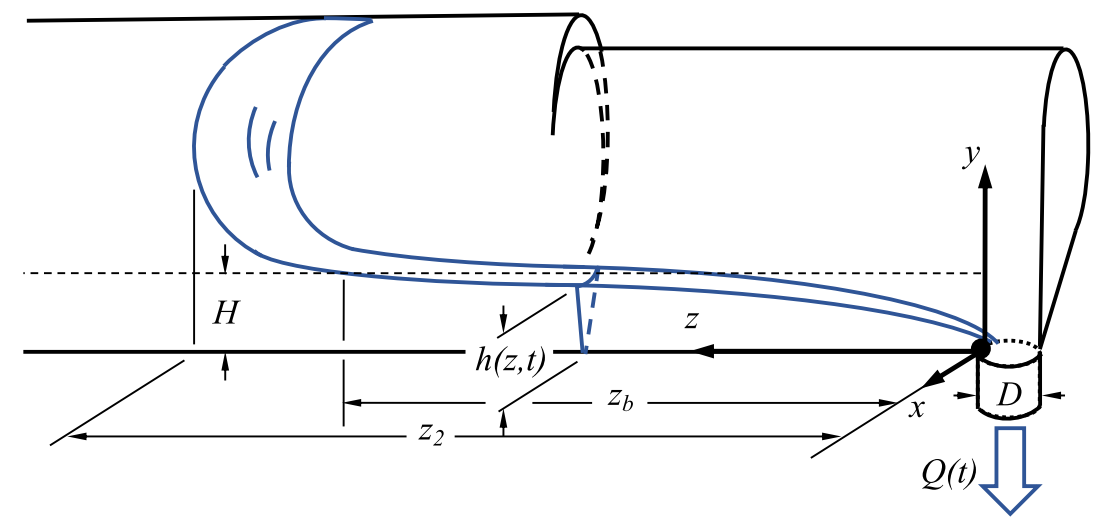

b

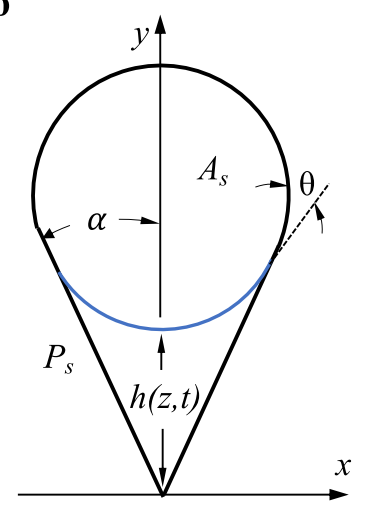

Fig. 4 Single drain definition sketch. Single drain flow sketched for ICF-4: a Perspective profile and b cross-sectional view. Drain diameter $D=4 \mathrm{~mm}$ for all ICF test chambers.

comparisons to the newly reduced data. Figure $4 a$ provides a sketch of the single drain problem for the ICF-4 container. The $z$ axis runs along the interior corner vertex and defines the primary flow direction. For hydrophilic liquids satisfying the Concus-Finn corner wetting condition, as the liquid is removed at $z=0$, a "filament" of liquid in the region $z \in\left[0, z_{b}\right]$ flows in the negative $z-$ direction along the interior corner and out of the drain port as sketched in Fig. 4a and as shown in Supplementary Fig. 1a. The flow is primarily parallel, characterized by 1D cross-flow curvature as depicted in Fig. $4 b$. The liquid occupying $z \in\left[z_{b}, \infty\right]$ is referred to as the bulk flow region with location $z_{2}$ denoting the bulk meniscus advancing front. This region is characterized by quasisteady 2D curvature. The dynamical boundary condition $H\left(z_{b} ; t\right)$ marks the matching region between effectively $2 \mathrm{D}$ bulk and $1 \mathrm{D}$ corner flow regimes. During draining, along the corner the capillary pressure becomes increasingly negative as $z$ approaches 0 , since capillary pressure $P(z)=-\sigma\left(1 / R_{1}+1 / R_{2}\right) \approx-\sigma / R$ (low streamwise curvature implies $\left.R_{2} \approx 0\right)$ where $R=R(z, t)=f h(z, t)$ and $f$ is a cross-flow interface curvature function. The resulting capillary pressure gradient drives liquid from higher to lower depths which are lowest at the drain port. Conserving volume, as the incompressible liquid is removed at the drain location the bulk meniscus advances (or recedes depending on your point of view) and the overlying gas expands as the pressure in the container decreases. Though neglected herein, we note that such decompression can lead to gas exchange across the liquid-free surface ${ }^{35}$.

In general ${ }^{36}$, we can assume a container geometry with $n$ geometrically wetted interior corners satisfying the Concus-Finn condition. Let $j$ serve as an index for a given wetted interior corner flow, where $j=1,2, \ldots n$ for $n$ total interior corners. Figure 4 depicts the purposely simplified ICF-4 container with a single $n=1$ interior corner of half angle $a_{j}$. While a variety of moving contact line models $s^{37,38}$ and subsequent solution techniques abound ${ }^{39,40}$, note here that the flow is largely parallel to the contact line allowing us to satisfactorily employ a constant contact angle $\theta$ condition. At long times $z_{2}(t)=z_{b}(t)+$ const and from a priori predictions $s^{41-43}$ and a posteriori measurements ${ }^{44}$ it can be shown for quasi-static liquids in semi-infinite columns under microgravity conditions that $H_{j}(z, t)=$ const given by

$H_{j}=\frac{P_{s} \cos \theta}{2 \Sigma f_{j}}\left(1-\left(1-\frac{4 \Sigma A_{s}}{P_{s}^{2} \cos ^{2} \theta}\right)^{1 / 2}\right)$,

where $P_{s}$ is the perimeter of the container section, $A_{s}$ is the container cross-sectional area, and $\Sigma, F_{A j}$, and $f_{j}$ are the dimensionless normalized total wetted corner cross-sectional flow area, jth corner cross-sectional flow area, and jth corner cross-flow interface curvature functions, respectively:

$\Sigma=\sum_{j=1}^{n} \frac{F_{A j}}{f_{j}^{2}}, \quad F_{A j}=f_{j}^{2}\left(\frac{\cos \theta \sin \delta_{j}}{\sin a_{j}}-\delta_{j}\right), \quad f_{j}=\frac{\sin a_{j}}{\cos \theta-\sin a_{j}}$,

where $\delta_{j} \equiv \pi / 2-a_{j}-\theta . H_{j}=h_{j}\left(z_{2}(t)\right)$ serves as the key dynamical boundary condition for the corner flow analysis. Because $H_{j}$ is known as a function solely of the geometry and wetting conditions of the container, it is known a priori and used to scale the governing momentum equations. Thus, by choosing scales

$z \sim L, \quad h \sim H, \quad t \sim A_{s} L / Q_{s}, \quad Q_{s} \sim \sum_{j=1}^{n} F_{A j} F_{i j} H_{j}^{3} / L$,

assuming a slender interior corner flow satisfying $H_{j}^{2} / L^{2} \ll 1$, the governing system reduces to a single dimensionless $z$-component visco-capillary momentum equation which may be solved along with the continuity equation to find solutions for what are henceforth denoted by dimensionless height $h_{j}(z, t)=h_{1}(z, t) \equiv h(z$, $t$ ), drain rate $Q(t)$, and bulk meniscus advance rate $z_{b}(t)$. (We note that $F_{i}=F_{i}(a, \theta)$ is a weak geometric viscous flow resistance function such that $1 / 8 \leq F_{i} \leq 1 / 6$.) The $O(1)$ self-similar solutions for such a single interior corner container are

$h(z, t)=\left(z(3 / 2 t)^{1 / 2}\right)^{1 / 3}$

$Q(t)=(1 / 6 t)^{1 / 2}$,

$z_{b}(t)=(2 t / 3)^{1 / 2}$

For weakly tapering (subscript $T$ ) nonconstant cross-section containers, the bulk meniscus height Eq. (2) may be approximated employing $A_{s}(z)$ and $P_{s}(z)$, yielding a $z$-dependent corner flow height condition where $h_{j}\left(z_{b}(t), t\right)=H_{j}\left(z_{b}\right)$. For a linear taper as in the case of ICF-9, the $O(1)$ analytic solutions for dimensionless height $h_{T}(z, t)$, drain rate $Q_{T}(t)$, and bulk meniscus advance rate 
Table 1. ICF-1 fluid properties, scales, and constraints. Subscript 1 denotes the primary $a_{1}=30^{\circ}$ corner.

\begin{tabular}{|c|c|c|c|}
\hline Property & Units & ICF-1 small & ICF-1 big \\
\hline Density, $\rho$ & $\mathrm{kg} \mathrm{m}^{-3}$ & 950 & 950 \\
\hline Viscosity, $\mu$ & $\mathrm{kg} \mathrm{m}^{-1} \mathrm{~s}^{-1}$ & 0.019 & 0.019 \\
\hline Surface tension, $\sigma$ & $\mathrm{N} \mathrm{m}^{-1}$ & 0.0206 & 0.0206 \\
\hline Contact angle, $\theta$ & deg & $0^{\circ}$ & $0^{\circ}$ \\
\hline Scales & Units & ICF-1 small & ICF-1 big \\
\hline Half angle, $a_{1}$ & deg & $15^{\circ}$ & $15^{\circ}$ \\
\hline Flow length, $L$ & $\mathrm{~mm}$ & $\begin{array}{l}49 \\
60,46,56\end{array}$ & $\begin{array}{l}58, \\
58,50,36\end{array}$ \\
\hline Height, $H_{1}$ & $\mathrm{~mm}$ & $\begin{array}{l}\text { 12.0, } 11.5 \\
10.7,11.1\end{array}$ & $\begin{array}{l}11.6,11.6, \\
11.9,12.5\end{array}$ \\
\hline Perimeter, $P_{s}$ & $\mathrm{~mm}$ & $\begin{array}{l}90 \\
87,81,84\end{array}$ & $\begin{array}{l}88, \\
88,90,94\end{array}$ \\
\hline Surface area, $A_{s}$ & $\mathrm{~mm}^{2}$ & $\begin{array}{l}321,299 \\
259,277\end{array}$ & $\begin{array}{l}302,302, \\
318,347\end{array}$ \\
\hline Geometry, $F_{i 1}$ & - & 0.141 & 0.141 \\
\hline $\begin{array}{l}\text { Velocity, } W_{1}= \\
\sigma \sin ^{2} a_{1} F_{i 1} / \mu f_{1}\end{array}$ & $\mathrm{~mm} \mathrm{~s}^{-1}$ & 29.3 & 29.3 \\
\hline $\begin{array}{l}\text { Flow rate, } Q= \\
\sum_{j=1}^{3} W_{j} F_{A_{j}} H_{j}^{3} / L\end{array}$ & $\mathrm{~mm}^{3} \mathrm{~s}^{-1}$ & $\begin{array}{l}302,222 \\
233,213\end{array}$ & $\begin{array}{l}234,234, \\
293,465\end{array}$ \\
\hline Time, $t \sim A_{s} L / Q$ & s & $\begin{array}{l}52, \\
81,51,73\end{array}$ & $\begin{array}{l}75, \\
75,54,27\end{array}$ \\
\hline Time offset, $t_{0}$ & - & $3 / 2$ & $3 / 2$ \\
\hline $\begin{array}{l}\text { Lubrication } \\
\text { assumptions }\end{array}$ & Constraint & ICF-1 small & ICF-1 big \\
\hline $\begin{array}{l}\text { Slender geometry, } \\
\epsilon_{1}=H_{1} / L\end{array}$ & $\epsilon_{1}^{2} \ll 1$ & $<0.05$ & $<0.112$ \\
\hline Capillary dominance & $B o \ll 1$ & $\sim 10^{-4}$ & $\sim 10^{-4}$ \\
\hline $\begin{array}{l}\text { Low streamwise } \\
\text { curvature }\end{array}$ & $\epsilon_{1}^{2} f_{1} \ll 1$ & $<0.019$ & $<0.04$ \\
\hline Low intertia & $\epsilon_{1}^{2} \rho \sigma H_{1} \sin ^{4} a_{1} /\left(f_{1} \mu^{2}\right) \ll 1$ & $<0.4$ & $<1.0373$ \\
\hline Low normal stress & $\epsilon_{1}^{2} \sin ^{2} a_{1} \ll 1$ & $<0.0036$ & $<0.008$ \\
\hline Low saturation limit & $\beta /(1-\beta) \ll 1$ & 0.1516 & 0.1516 \\
\hline Static CL & $\epsilon_{1} \beta \sin ^{2} a_{1} / f_{1} \ll 1$ & $<0.0059$ & $<0.0087$ \\
\hline $\begin{array}{l}\text { Concus-Finn } \\
\text { wetting }\end{array}$ & $\theta<90^{\circ}-a_{1}$ & satisfied & satisfied \\
\hline
\end{tabular}

$z_{b T}(t)$ for such container types are

$$
\begin{aligned}
& h_{T}(z, t)=H\left(z_{b T}\right)\left(z / z_{b T}\right)^{1 / 3}, \\
& Q_{T}(t)=t^{2} / 27, \\
& z_{b T}(t)=t / 3 .
\end{aligned}
$$

We measure and report the dimensionless interfacial height profiles $h(z, t)$, volumetric flow rate $Q(t)$, and bulk advancing front $z_{2}(t)$ as functions of time with each plot overlaid with the analytic solutions of Eqs. (5)-(7), or Eqs. (8)-(10), respectively. Test vessels ICF$1,-2,-3,-4,-6,-8$, and -9 are reported below in numerical order for all single drain tests conducted on-orbit. The ICF-1, -2, -3, -4, and - 6 vessels are longitudinally asymmetric. As such, draining from each end changes the characteristic geometric scales of the flow, effectively establishing two distinct experimental conditions for each test cell depending on which end is drained. Thus, there are two draining data sets for each test cell for vessels ICF-1, -2, - 3, -4, and -6.

Most of the ICF test cells were drained multiple times during the ISS experiments. We report all drains and denote the ith drain as 'Run $i^{\prime}$. Despite $60 \mathrm{fps}$ video, all data were collected at either 1 or $0.2 \mathrm{~Hz}$ frequencies depending on the drain rate of the particular test. For any given run, hundreds of interface height profiles $h(z, t)$ are digitized as shown in Fig. 3b for ICF-4. The analytical solutions are employed to collapse such data. For example, a rearrangement of Eq. (5) applied in Fig. $3 c$ provides the favorable collapse indicated by the slope of unity (plot scale not 1-to-1). The favorable linear collapse of the data is clear despite noise due to the spurious digitization errors of the automated tracking algorithm. To filter the data into a single curve we timeaverage the collapsed data for each run generating a single interface profile curve as identified by the black line, say, in Fig. 3c. As time elapses, the bulk meniscus advances, increasing the $z$-domain over which $h(z, t)$ is defined. This reduces the number of time-average samples at further downstream locations as time increases.

The experiments require a certain amount of time to establish something resembling a self-similar height profile. Only after this "start-up" period is it valid to compare the experiments with the long-time similarity solutions of the lubrication model. We thus introduce a time offset $t_{0}$ for each flow. We calculate $t_{0}$ as the time required for dimensionless $z_{b}$ to advance from 0 to 1 , or the time it would take for a fully-filled tank to drain until the measured bulk meniscus occupies the initial experiment volume recorded. Mathematically, this implies that $t_{0}=3 / 2$ per Eq. (7) with $z_{b}=1$ for constant cross-sectional vessels, and $t_{0}=3$ per Eq. (10) for tapered conduits. Test cell ICF-8 is categorically unique and requires a different $t_{0}$ value as will be discussed.

\section{ICF-1}

An image, solid model, wire model, and big-end draining image were presented in Fig. 1 for the ICF-1 test vessel. This test cell was drained several times from each end ("small-end" and "big-end"). The section is a 75-30-75 isosceles triangle. The faces of this truncated triangular pyramid taper weakly at $3.155^{\circ}$. Due to this shallow angle, the constant cross-sectional predictions of Eqs. (5)-(7) may be used to compare to the data collected for this geometry. The interface profiles $h(z, t)$ are tracked at least to the intersection of $h(z, t)$ with $H(z)$ calculated from Eq. (2). The triangular section establishes $n=3$ corner drains since all of the interior corners are critically wetted. Thus, three simultaneous interior corner flows take place during the single draining port process. The $75^{\circ}$ corner flows bifurcate and flow along the even lower flow rate $90^{\circ}$ corners formed by the base (big-end) or lid (small-end) before joining the draining flow at the exit port, which is aligned for imaging only the $30^{\circ}$ corner flow in profile. Despite such complexities, the lubrication model for the three interior corner draining flows may be solved for comparisons to the data with expectations of over-prediction. The model is also employed to estimate that the two $75^{\circ}$ corners together contribute $\approx 3 \%$ to the drain rate. Further details of the flow are listed in Table 1.

Figure $5 \mathrm{a}$ displays the ICF-1 results for the advancing bulk meniscus $z_{2}$ for the case of small-end draining ( $V_{1}$ closed and $V_{2}$ opened, Fig. 1a). Maximum discrepancies are $11 \%$ at the end of Run 2. The volumetric drain rates $Q$ displayed in Fig. $5 \mathrm{~b}$ are in qualitative agreement with the analysis. Quantitative comparisons are somewhat difficult to establish due to a certain lack of control of the drain rate. For example, gas ingestion at the drain exit port occurred in nearly all runs. When this occurred the astronauts would temporarily stop the draining and allow the passive capillary flow of liquid to displace the ingested gas, i.e., Fig. 3 (middle image). Furthermore, the large piston diameter of $38 \mathrm{~mm}$ leads to a fairly insensitive measure of flow rate based on timedependent piston location and flow rate on the order of $220 \mu \mathrm{m} / \mathrm{s}$. The latter point is addressed by fitting a curve to the piston location, such as Supplementary Fig. $2 a$ and time-differentiating the smoothed curve, rather than differentiating the discrete piston locations, Supplementary Fig. 2b. Nonetheless, we report volumetric flow rate average uncertainties $<28 \%$ for all runs. Draining ICF-1 from the small-end allows $H(z)$ to increase with $z$. As such, 
a

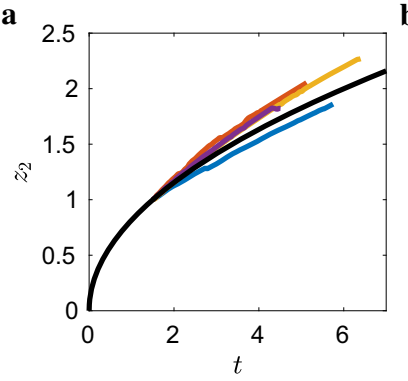

d

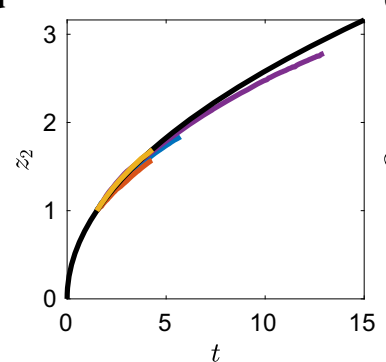

b

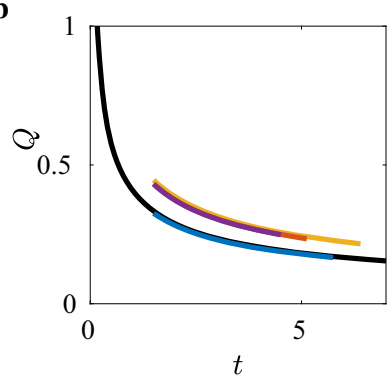

e

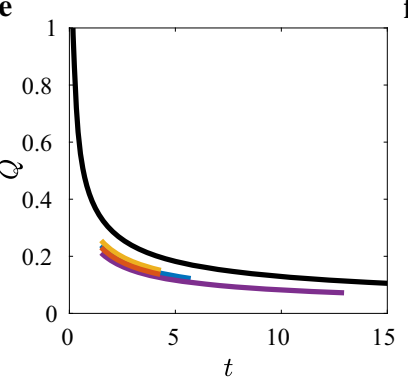

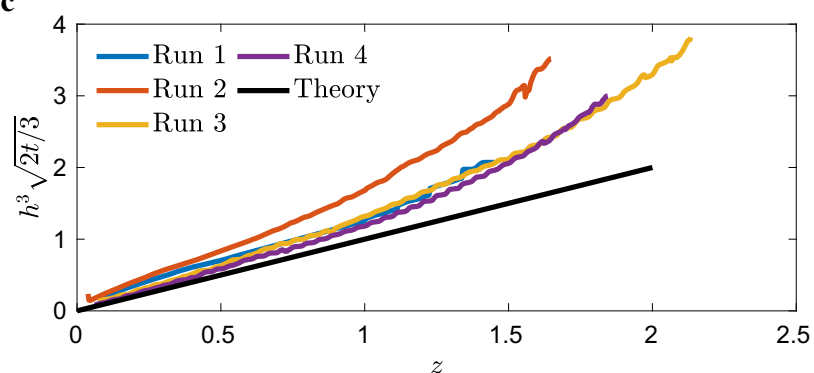

f

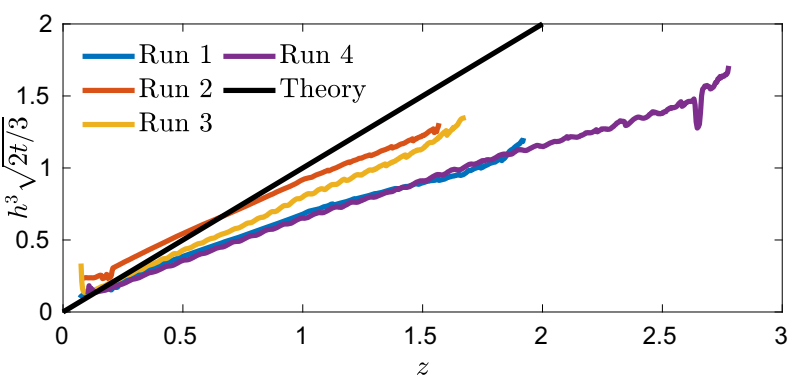

Fig. 5 Reduced ICF-1 test cell drain data. Draining from small-end a-c and big-end d-f. a and d plot advancing bulk meniscus location $z_{2}(t)$, b and e volumetric flow rate $Q(t)$, and $\mathbf{c}$, $\mathbf{f}$ the self-similar time-averaged interface height profile $h^{3} \sqrt{2 t / 3}$, each overlaid with analytic solutions (black) of Eqs. (7), (6), and (5), respectively.

the meniscus is expected to overshoot the constant height solution computed assuming a constant cross-section. Figure $5 \mathrm{c}$ confirms this, as all four test runs overshoot the constant height prediction. Despite the overshoot, data still scales with Eq. (5) and maintains the same order of magnitude.

Figure $5 \mathrm{~d}$ presents $z_{2}(t)$ for draining from the big-end of the ICF1 test cell $\left(V_{1}\right.$ opened and $V_{2}$ closed, Fig. 1a). Maximum discrepancies are $7 \%$ by the end of Run 2. Similar to the smallend drain, $Q$ follows the theory fairly well considering the aforementioned experimental complications, agreeing within $<22 \%$. Draining ICF-1 from the large-end allows $H(z)$ to decrease with $z$. Consequently, $h(z, t)$ is expected to undershoot the constant height solution as observed in Fig. $5 \mathrm{f}$.

\section{ICF-2}

The ICF-2 test cell was similarly drained from small- and big-ends. Though the ICF-2 test cell side walls taper at $8.95^{\circ}$, it can be shown that the impact of this taper is weak on the flow and that the height condition quickly establishes a nearly constant value of $H$ $(z) \approx D / 2 f=0.207 D$ (where $D=23 \mathrm{~mm}$ ), which varies $<10 \%$ for the flow. Thus, again the drain data collected for ICF- 2 may be best compared to the constant cross-sectional predictions of Eqs. (6), (7). As highlighted in Supplementary Fig. 4, the rectangular crosssection establishes $n=4$ simultaneous interior corner flows. The ICF-2 values are tabulated in a similar manner as in Table 1 for ICF1 , see Supplementary Table 1. Figure 6a presents $z_{2}$ drained from the small-end ( $V_{1}$ closed and $V_{2}$ opened, Supplementary Fig. $4 a$ ), which are nearly coincident, showing maximum error with the lubrication prediction within $5 \%$. Figure $6 c$ presents $Q(t)$, the summation of the four corner flows, which agrees with the lubrication model within $12 \%$. Corner flow height profiles $h(z, t)$ for ICF-2 can not be digitized for this test cell due to the nonorthogonal viewing angle as observed from Supplementary Fig. $4 \mathrm{~d}$. The big-end ( $V_{1}$ opened and $V_{2}$ closed, Supplementary Fig. $4 \mathrm{a}$ ) was drained only once. The results of this test for $z_{2}$ and $Q$ are shown in Fig. $6 b$ and $d$, where only qualitative agreement is observed with the model predictions.

\section{ICF-3}

The ICF-3 test cell was also drained from both small- and big-ends. During draining, the advancing front was drained while only residing within a constant cross-section of the test cell-the step geometry was not encountered. The data were thus compared to the constant cross-sectional predictions of Eqs. (5)-(7). The snowcone cross-section sketched in Supplementary Fig. 5 implies $n=1$ edge. Additional data for these tests are provided in Supplementary Table 2. Figure 7a presents results for the advancing front $z_{2}$ drained from the small-end ( $V_{1}$ closed and $V_{2}$ opened, Supplementary Fig. 5a), and while only two runs were conducted, the advancing front of each is nearly coincident. Excellent agreement with the lubrication prediction is observed, of which the maximum error of both runs is $<3.5 \%$. Figure $7 \mathrm{~b}$ presents $Q(t)$, with maximum errors for both runs $<12 \%$, which is favorable agreement considering the limitations discussed in section ICF-1. The selfsimilar analytic interfacial height over-predicts the observed height. This could be explained via inertial effects, which are not necessarily small for this test.

Similar results are observed for the ICF-3 big-end drain $\left(V_{1}\right.$ opened and $V_{2}$ closed, Supplementary Fig. 5a). Figure $7 d$ presents $z_{2}$ as a function of time, which is over-predicted by the lubrication prediction with maximal error $<8.5 \%$. This could be due to the volumetric flow rate, which is also over-predicted by the theory on average $<14 \%$, Fig. 7 e. The self-similar analytic interfacial height shows excellent agreement for domains near the drain, but as the advancing front continues, downstream heights are increasingly over-predicted by the theory, Fig. 7f. Again, the large inertia of these test might explain this observation.

\section{ICF-4}

The ICF-4 test cell was also drained from each end. A constant cross-section was maintained during draining-the step geometry was not encountered. The data is thus compared to the constant cross-sectional predictions of Eqs. (5)-(7). The ice-cream-cone cross-section of Supplementary Fig. 6 implies $j=1$. Figure 8 a presents $z_{2}$ alongside the theoretical prediction, with maximum error $<14 \%$ for the small-end draining ( $V_{1}$ closed and $V_{2}$ opened, Supplementary Fig. 6a). Additional data for these tests are 


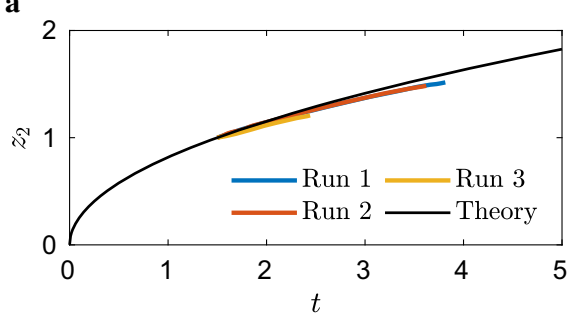

c

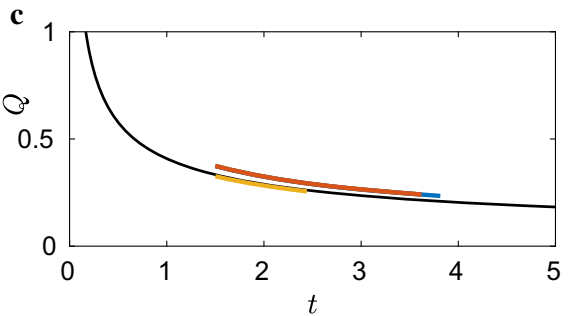

b
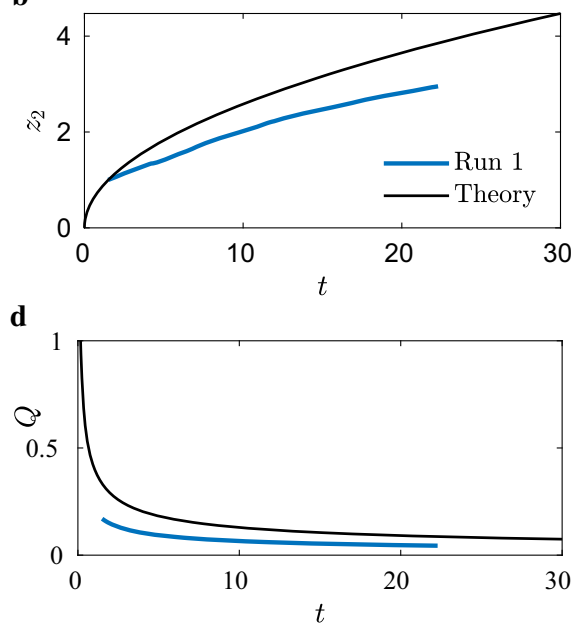

Fig. 6 ICF-2 data. ICF-2 advancing bulk meniscus location $z_{2}(t)$ and volumetric flow rate $Q(t)$. a, $\mathbf{c}$ small-end drain and $\mathbf{b}$, $\mathbf{d}$ large-end drain.

a
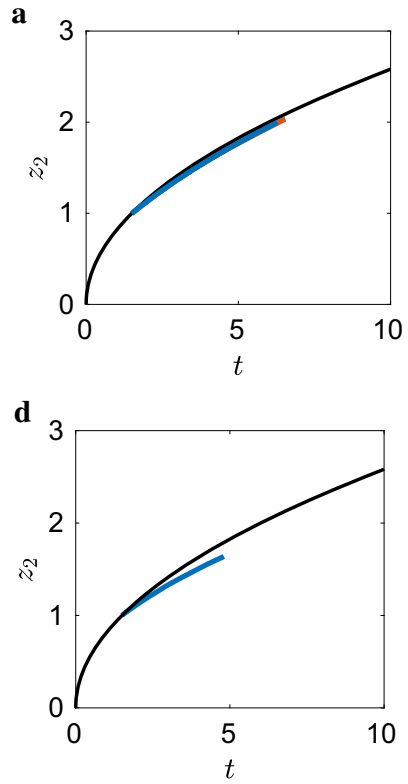

b

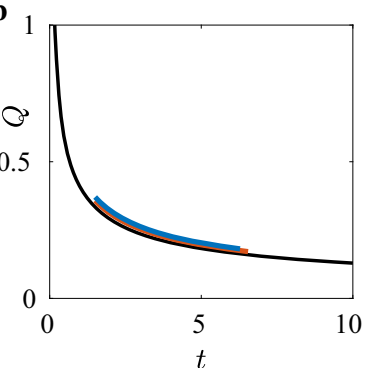

e

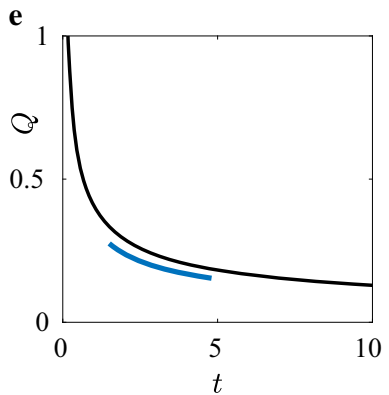

c

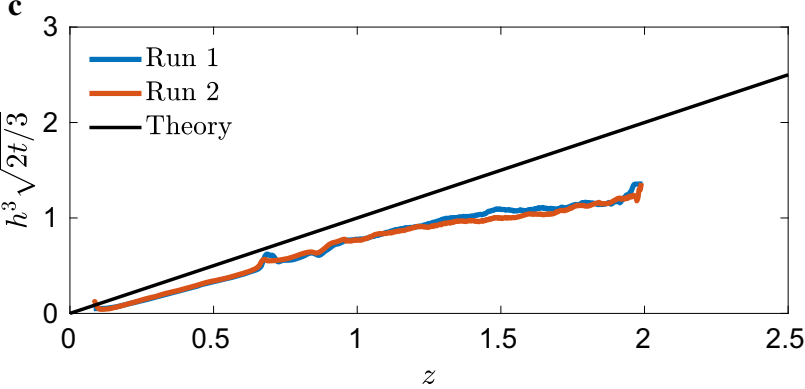

f

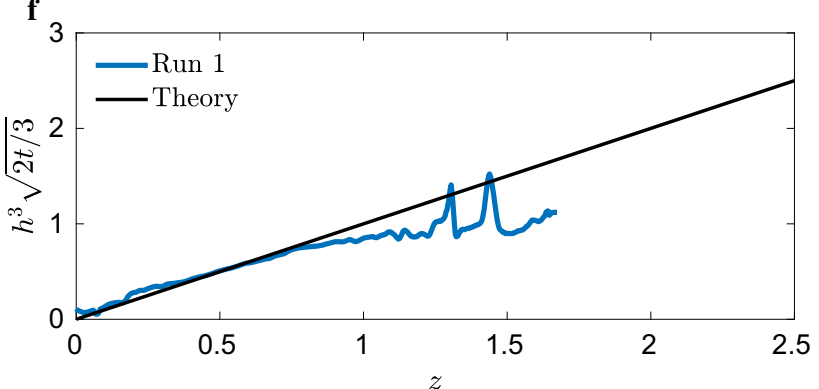

Fig. 7 ICF-3 data. ICF-3 test cell drained from a-c small- and $\mathbf{d}-\mathbf{f}$ big-ends. $\mathbf{a}$, $\mathbf{d}$ advancing bulk meniscus location $z_{2}(t)$, $\mathbf{b}$, e volumetric flow rate $Q(t)$, and $\mathbf{c}, \mathbf{f}$ the self-similar time-averaged interface height profile $h^{3} \sqrt{2 t / 3}$, each overlaid with theory (black), Eqs. (7), (6), and (5), respectively.

provided in Supplementary Table 3. The volumetric flow rate follows the theoretical curve for later times but is nearly constant for the duration of the runs. Figure $8 \mathrm{c}$ plots the self-similar interfacial height profiles. Noise is measured in regions $z \in[0.5,1]$, where unfavorable lighting complicates interface tracking. Regardless, the theory under-predicts $h(z, t)$, which is not explained by the relatively high inertia. However, the volumetric flow rate is less than the theoretical flow rate, Fig. $8 \mathrm{~b}$. The theory assumes zero height at the drain, but in many runs, the astronauts were only able to reduce drain height to between 2 to $3 \mathrm{~mm}$ without ingesting gas (see drain port details, Fig. 4). With average drain rates $<23 \%$ in the prediction, it is expected the meniscus heights are lower, and the advancing front is slower, both of which are observed.

Big-end drain ( $V_{1}$ opened and $V_{2}$ closed, Supplementary Fig. 6a) results are similar and Fig. $8 \mathrm{~d}$ presents $z_{2}$ against Eq. (7) with errors $<13 \%$. The volumetric flow rate shown in Fig. $8 \mathrm{e}$ exhibits qualitative agreement to theory $<27 \%$, as discussed in section
ICF-1. For this run, the lubrication prediction accurately predicts meniscus interfacial height, with an average error $<9 \%$, Fig. 8 .

\section{ICF-6}

The ICF- 6 test cell was also drained from each end. The linearly tapered diagonal vane runs the length of the test cell establishing significantly different drain geometries depending on the end drained, Supplementary Fig. 7a. The end with the zero vane height is referred to as the big-end and the end with the vane height that spans the diagonal is referred to as the small-end. In both drain scenarios, the bulk meniscus is assumed to advance through a constant cross-section, though it is clearly complicated by the presence of the pinning edges of the vane for varying portions of the flow. Such conditions are not addressed by the lubrication model. As sketched in Supplementary Fig. 7c, the square section contains four corners, but the vane divides the section into two 45-90-45 isosceles triangles with primary drain path along the 

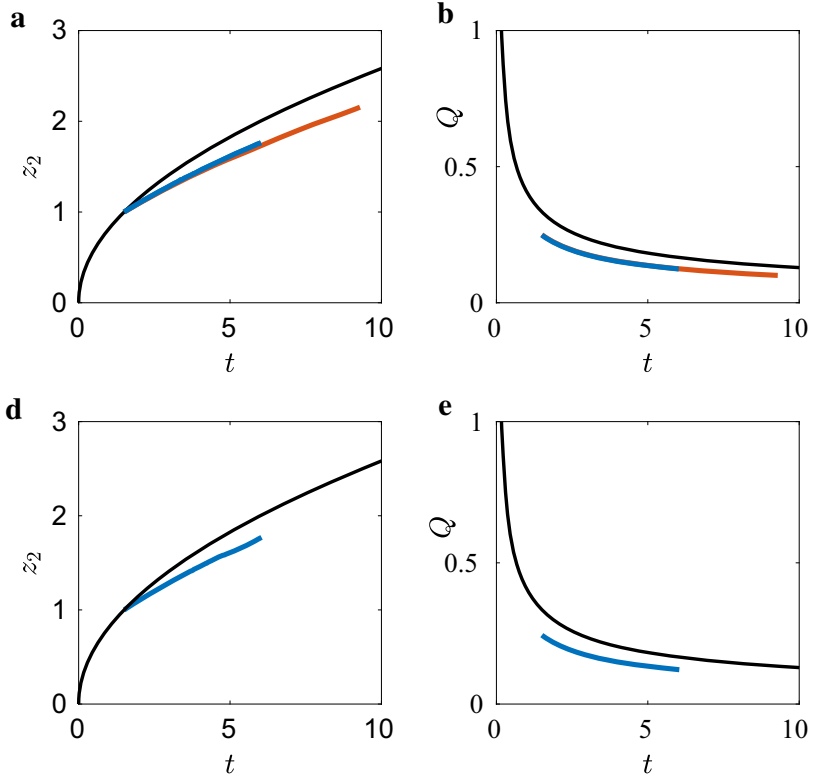
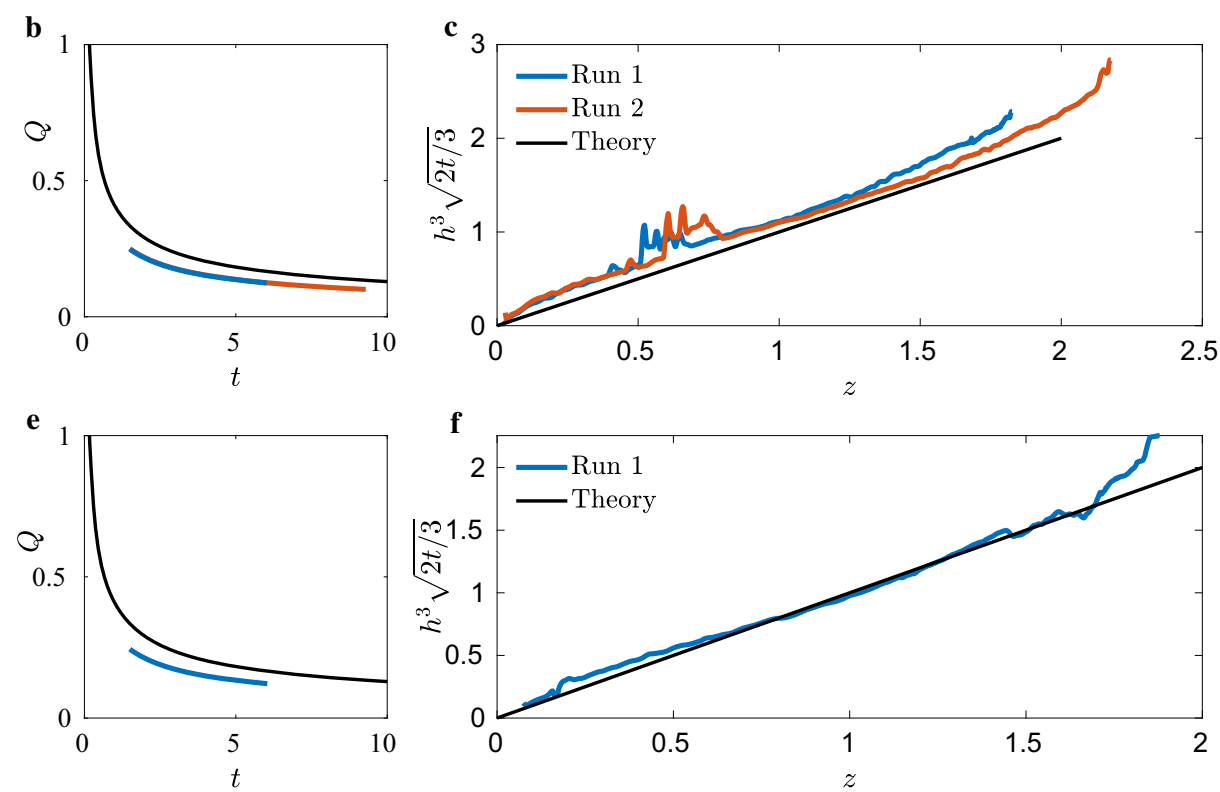

Fig. 8 ICF-4 data. a-c Small-end and $\mathbf{d}-\mathbf{f}$ big-end drain. $\mathbf{a}$, $\mathbf{d}$ present advancing bulk meniscus location $z_{2}(t)$, b, e volumetric flow rate $Q(t)$, and c, $\mathbf{f}$ the self-similar time-averaged interface height profile $h^{3}(2 t / 3)^{1 / 2}$.
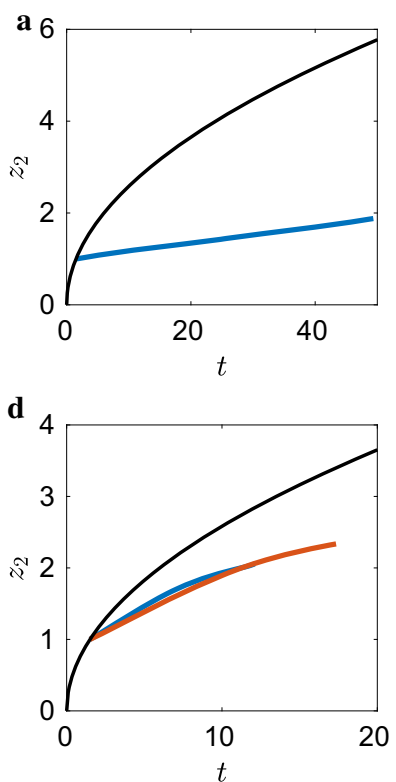
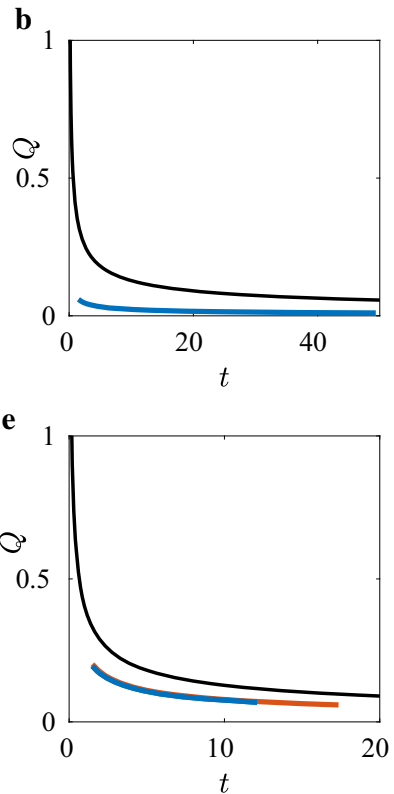
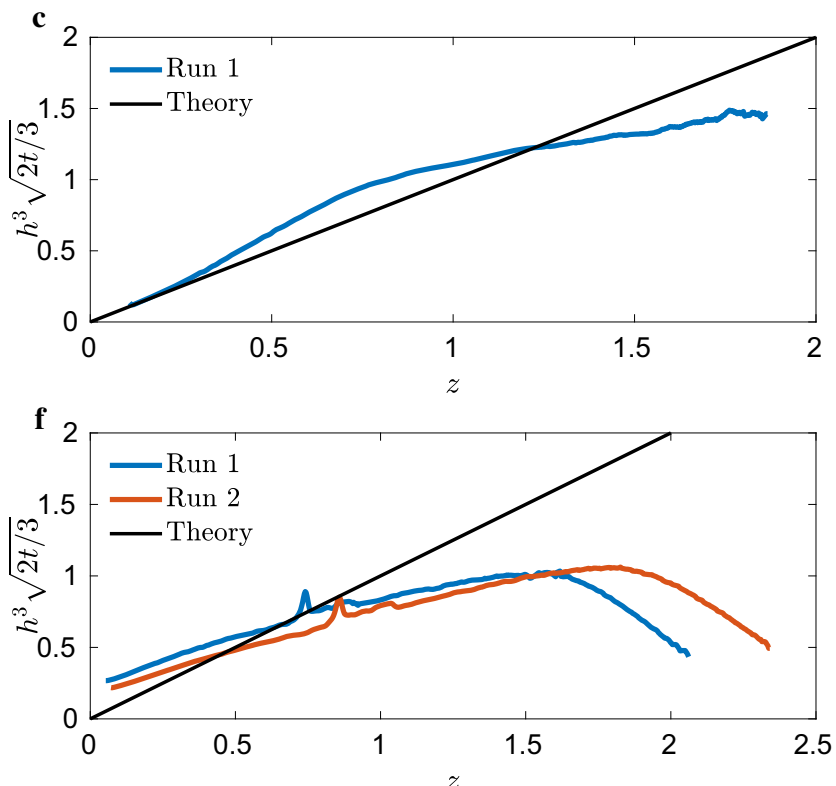

Fig. 9 ICF-6 data. Draining from a-c small- and $\mathbf{d}$-f big-ends. a, $\mathbf{d}$ present advancing bulk meniscus location $z_{2}(t)$, b, e volumetric flow rate $Q(t)$, and $\mathbf{c}, \mathbf{f}$ the self-similar time-averaged interface height profile $h^{3}(2 t / 3)^{1 / 2}$.

$a_{1}=22.5^{\circ}$ interior corner formed by the vane and side wall, where the $1 \mathrm{~mm}$ thick vane bisects each drain port. The drain detail in Supplementary Fig. 7c illustrates how the drain port spans the diagonal vane such that fluid is simultaneously removed from both sides of the vane. Though the theory is inappropriate for this test cell, we apply it anyway. We model the flow with $n=5$ edges: two $45^{\circ}$ corners $\left(a_{1}=22.5^{\circ}\right)$ and three $90^{\circ}$ corners $\left(a_{2}=45^{\circ}\right)$, for a total flow rate of $Q=2 Q_{1}+3 Q_{2}$. Additional data for these tests are provided in Supplementary Table 4 . We note that $2 Q_{1}$ is $\sim 30$ times larger than $3 Q_{2}$, implying that the flow is dominated by the two $45^{\circ}$ vane corners, Fig. 9d. Figure 9a shows the bulk meniscus as drained from the big-end ( $V_{1}$ opened and $V_{2}$ closed, Supplementary Fig. 7a), which is over-predicted by poorly equipped Eq. (7). The bulk meniscus is nearly linearly in time, which suggests the vane acts as a tapered geometry though significantly slower than the $1 / 3$ temporal slope, Eq. (10). The volumetric flow and bulk meniscus advance rates are significantly less than the theoretical predictions, Fig. $9 \mathrm{~b}$. This suggests that the impact of the contact line pinning along the vane edge is to flatten the interface corner menisci effectively increasing the contact angle in turn reducing the capillary pressure gradient and flow velocity. These flows are clearly complicated by contact line pinning along the vane edge as the vane height decreases, which is not currently accounted for in the theory. An effort to derive a more representative set of dynamical boundary conditions for $H$ (z) may prove fruitful. 

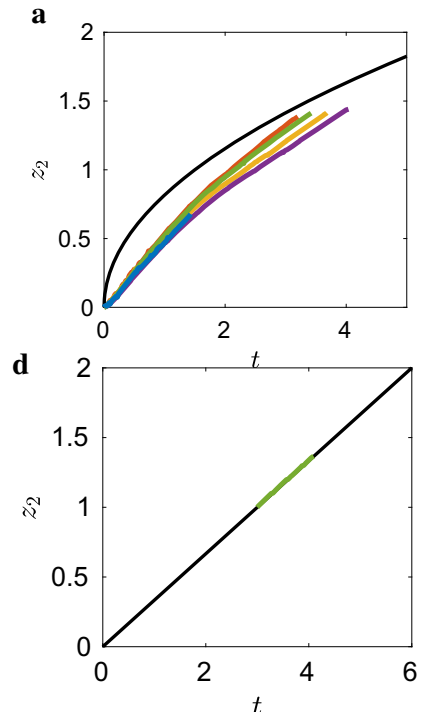
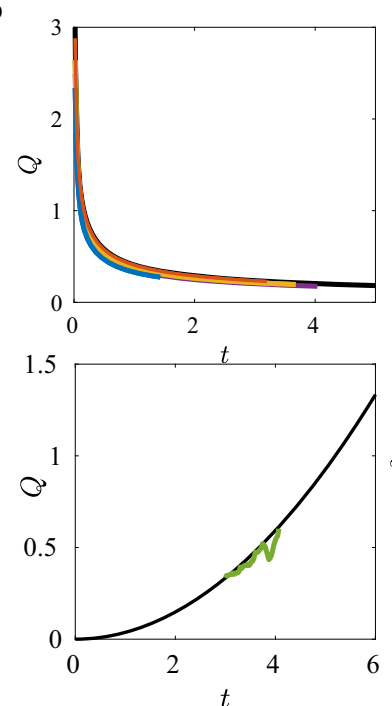
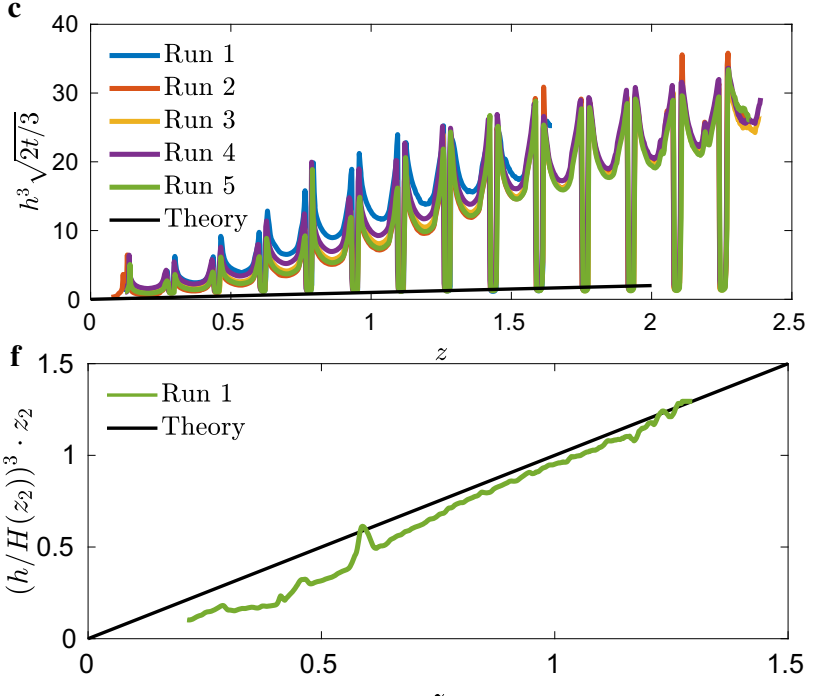

Fig. 10 ICF-8 and -9 data. Single drain data for ICF-8 and -9 cells. a-c: ICF-8 drain data. a Bulk advancing front $z_{2}$, b volumetric flow rate $Q$ plotted against time, and c self-similar time-averaged interfacial height $h^{3}(2 t / 3)^{1 / 2}$, each overlaid with analytic solutions (black) from Eqs. (5), (6), and (7), respectively. d-f: ICF-9 drain data in the linearly tapered section. d Bulk advancing front location $z_{2}(t)$ and e volumetric flow rate $Q$ $(t)$, and $\mathbf{f}$ the self-similar time-averaged interfacial height with the respective analytic solutions of Eqs. (10), (9), and (8) (black).

The ICF-6 small-end drain ( $V_{1}$ closed and $V_{2}$ opened, Supplementary Fig. 7a) bulk meniscus $z_{2}$ is also seen to undershoot the lubrication theory, Fig. 9d. Again, large effectively pinned contact angles in part explains the slower advancing front, Fig. 9e. But in this case, in particular, the meniscus height $h(z, t)$ and bulk meniscus height $H\left(z_{b}, t\right)$ are effectively held down by vane edge pinning. A special application of Concus-Finn theory to establish tapered vane pinned contact line conditions and an improved $H$ $\left(z_{b}, t\right)$ would be required to make the lubrication model more quantitatively applicable for this "weakly tapered" test cell type.

\section{ICF-8}

Supplementary Fig. 8 provides an image, solid model, and wire model for the ICF-8 test vessel. The test cell is a constant icecream-cone section interrupted by vane partitions that divide the interior corner region incrementally in the primary flow direction while allowing flow through an opening near the vertex of the interior corner. We note that the height of the opening is approximately equal to the constant height boundary condition $H$ for the ice-cream-cone section container without the partitions. In the absence of any other analytical model for this geometry, we again employ the constant cross-section lubrication approximations of Eqs. (5)-(7) in remote hopes of qualitative assessment. Unlike the other drain tests, the ICF-8 data does not account for an initial time offset $t_{0}$ and the flow does not conform to the negligible streamwise curvature assumption of the lubrication theory. We apply it nonetheless. The ice-cream-cone cross-section (Supplementary Fig. 8c) implies $n=1$. The bulk meniscus initially advances slower than the predictions, but it is clear given longer drain times the bulk meniscus would overtake the lubrication prediction due to non-negligible streamwise curvature and the liquid wetting the partitions. From Fig. $10 \mathrm{c}$ it is observed how poorly the liquid profile $h(z, t)$ is captured by the analysis, the discrete non-negligible streamwise curvature maintaining levels far in excess of the Concus-Finn theory predictions for $H\left(z_{b}\right)$. Surprisingly, volumetric flow rates favorably agree with the lubrication prediction within $2 \%$, as shown in Fig. 10b. We conjecture that this potentially coincidental finding may be due to the fact that streamwise curvature is nearly constant and equal for all vane segments and that the viscous resistance of the flow is governed by $H$ of the vane gap and not the actual $H$ of the flow. Additional data for these tests are provided in Supplementary Table 5.

\section{ICF-9}

The fully tapered geometry of ICF-9 shown in Supplementary Fig. 10 c establishes a flow geometry that unquestionably satisfies the tapered container drain theory, Eqs. (8)-(10). The equilateral triangular cross-section achieves $j=3$. Figure $10 \mathrm{~d}$ presents the advancing front $z_{2}(t)$ data, with draining from the small-end $\left(V_{1}\right.$ closed and $V_{2}$ opened, Supplementary Fig. 10a). Unlike all other weakly tapered test cells, ICF-9 exhibits a bulk meniscus that advances linearly in time, which agrees with theoretical predictions within a maximum error of $<1 \%$, as shown in Fig. 10e. As suggested by the theory, the maximum volumetric flow rate increases in time, unlike all other runs, with maximum error $<30 \%$ and average error $<10 \%$. The interfacial height also compares favorably to the analytic solution Eq. (8), with an average error $<20 \%$, Fig. 10f. The ICF- 9 test cell satisfies the assumptions of the model to the greatest extent with exceptionally low inertia up to two orders of magnitude lower than the other test cells. Additional data for this test is provided in Supplementary Table 6.

\section{DISCUSSION}

Altogether, we find that many of the "incidental" drain tests performed by the astronaut crews for the CFE-ICF experiments on ISS provide rare data of value for theoretical and numerical benchmarks. By digitizing all single drain events, over $2 \mathrm{~h}$ of flight data reported, from the CFE-ICF space experiments we are able to establish a limited, though rare, data set for such draining flows in containers with interior corners. We find that the experimental results are predicted fairly well by a simple zero-gravity quasisteady lubrication analysis.

In this 5-year post-flight data reduction investigation, a total of 27 experiment runs for seven of the nine CFE-ICF test vessels are mined and presented herein from the NASA PSI archive https://psi. nasa.gov/ for the draining flow phenomena in containers with interior corners. Referring to Fig. 2, several families of drain geometries are represented including tapering triangular sections 
(weak taper ICF-1 and strong taper ICF-9, both with $n=3$ wetted corners), tapering rectangular sections (ICF- 2 with $n=4$ wetted corners), stepped tapers (ICF-3 and -4 with $n=1$ wetted corners), square sections with tapered vanes (ICF- 6 with $n=5$ wetted corners), and partitioned constant cross-sections (ICF-8 with $n=1$ wetted corners). As a demonstration of the value of the data, we employ it to benchmark a simple lubrication model. The model assumes slender capillarity-driven flows along interior corners with negligible streamwise curvature and dynamical interface height boundary conditions (i.e., $z_{2}(t), H(z)$, etc.). We assess the validity of the model assumptions applicable to each of the ICF draining flow geometries while comparing the predictions with the data for flow rate $Q(t)$, advancing bulk meniscus $z_{2}(t)$, and corner flow profile $h$ $(z, t)$ when observable. Although the analysis might be tuned to each unique draining flow, our rather cavalier comparisons show average agreement with flow rates to within $\pm 21 \%$ and advancing bulk menisci to within $\pm 8 \%$ for the test cells conforming to theory, ICF-1, -2, -3, -4, -9. Specific discrepancies may be blamed on irregular manually induced draining mechanisms, finite meniscus height conditions at the drain location, non-negligible inertia, boundary condition violations, and the presence of spurious expanding bubbles. These deviations observed outline the direction of further theoretical work to address such geometric complexities as planar and curved wall interior corner, vane edge pinning boundary conditions, and local streamwise curvature, to name a few. Nonetheless, it appears the lubrication model provides an adequate prediction of interior corner flow draining in the low-g environment provided the flows are slender. Such predictions are valued for precious liquid recovery from containers and conduits in large-scale systems aboard spacecraft and smallscale systems on earth. Numerical benchmarks may be similarly pursued using the present data set.

The capillary drain data presented is extracted from the NASA archive for CFE, which was conducted on ISS over the 2010-2015 time frame. The archived, publicly-accessible image data is corrected for misalignment and diffraction and smoothed as necessary to provide a benchmarking data set for further theoretical and numerical model development, as well as for practical fluids system design. The effort demonstrates the untapped value of the image data stored on the NASA online archives.

\section{DATA AVAILABILITY}

The discretized data may be found at figshare public data repository here: https:// figshare.com/articles/dataset/Single_Drain_Data/16632472 ${ }^{45}$. An explanation of the data is provided in the Supplementary Data Tables and Data Usability Description.

\section{CODE AVAILABILITY}

The image tracking algorithms employed to track interface and piston locations may be accessed by contacting the authors.

Received: 14 July 2021; Accepted: 8 October 2021;

Published online: 11 November 2021

\section{REFERENCES}

1. Manakasettharn, S., Taylor, A. \& Krupenkin, T. N. Bio-inspired artificial iridophores based on capillary origami: fabrication and device characterization. Appl. Phys. Lett. 99, 97-100 (2011).

2. Tamim, S. I. \& Bostwick, J. B. The elastic Rayleigh drop. Soft Matter 15, 9244-9252 (2019).

3. Schutzius, T. M., Elsharkawy, M., Tiwari, M. K. \& Megaridis, C. M. Surface tension confined (stc) tracks for capillary-driven transport of low surface tension liquids. Lab a Chip 12, 5237-5242 (2012).

4. Wellmerling, K., Lehmann, C., Singh, A. \& Kirby, B. J. Microfluidic chip for label-free removal of teratoma-forming cells from therapeutic human stem cells. J. Immunol. Regen. Med. https://doi.org/10.1016/j.regen.2020.100030 (2020).
5. White, N. C. \& Troian, S. M. Why capillary flows in slender triangular grooves are so stable against disturbances. Phys. Rev. Fluids 4, 1-29 (2019).

6. Concus, P. \& Finn, R. On the behavior of a capillary surface in a wedge. Proc. Natl Acad. Sci. USA 63, 292-299 (1969).

7. Bankoff, S. G. Ebullition from solid surfaces in the absence of a pre-existing gaseous phase. Trans. Am. Soc. Mech. Eng. 79, 735-740 (1957).

8. Griffith, P. \& Wallis, J. D. The Role of Surface Conditions in Nucleate Boiling. Report No. 14 (MIT, 1958).

9. Kast, W. Bedeutung der Keimbildung und der instationären Wärmeübertragung für den Wärmeübergang bei Blasenverdampfung und Tropfenkondensation. Chem. Ing. Tech. 36, 933-940 (1964).

10. Weislogel, M. M.Capillary Flow in an Interior Corner. Ph.D. thesis, Northwestern Uni. (1996).

11. Weislogel, M. M. \& Lichter, S. Capillary flow in an interior corner. J. Fluid Mech. 373, 349-378 (1998).

12. Srinivasan, R. Estimating zero-g flow rates in open channels having capillary pumping vanes. Int. J. Numer. Methods Fluids 41, 389-417 (2003).

13. Weislogel, M. M. Some analytical tools for fluids management in space: Isothermal capillary flows along interior corners. Adv. Space Res. 32, 163-170 (2003).

14. Wu, Z., Huang, Y., Chen, X. \& Zhang, X. Capillary-driven flows along curved interior corners. Int. J. Multiph. Flow. 109, 14-25 (2018).

15. Kolliopoulos, P. et al. Capillary-flow dynamics in open rectangular microchannels. J. Fluid Mech. 911, A32-26 (2021).

16. Zhou, J. \& Doi, M. Universality of capillary rising in corners. J. Fluid Mech. 900, A29 (2021). https://doi.org/10.1017/jfm.2020.531.

17. Higuera, F. J., Medina, A. \& Liñán, A. Capillary rise of a liquid between two vertical plates making a small angle. Phys. Fluids 20,102102 (2008).

18. Ponomarenko, A., Quéré, D. \& Clanet, C. A universal law for capillary rise in corners. J. Fluid Mech. 666, 146-154 (2011).

19. Klatte, J., Haake, D., Weislogel, M. M. \& Dreyer, M. A fast numerical procedure for steady capillary flow in open channels. Acta Mechanica 201, 269-276 (2008).

20. Gurumurthy, V. T., Roisman, I. V., Tropea, C. \& Garoff, S. Spontaneous rise in open rectangular channels under gravity. J. Colloid Interface Sci. 527, 151-158 (2018).

21. Taher, A., Jones, B., Fiorini, P. \& Lagae, L. Analytical, numerical and experimental study on capillary flow in a microchannel traversing a backward facing step. Int. J. Multiph. Flow. 107, 221-229 (2018).

22. Li, Y. et al. Study of capillary driven flow in an interior corner of rounded wall under microgravity. Microgravity Sci. Technol. 27, 193-205 (2015).

23. Chen, Y., Weislogel, M. M. \& Nardin, C. L.Capillary-driven Flows along Rounded Interior Corners (Cambridge Univ. Press, 2006).

24. Gerlach, F., Hussong, J., Roisman, I. V. \& Tropea, C. Capillary rivulet rise in realworld corners. Colloids Surf. A Physicochem. Eng. Asp. https://doi.org/10.1016/j. colsurfa.2020.124530 (2020).

25. Ransohoff, T. C. \& Radke, C. J. Laminar flow of a wetting liquid along the corners of a predominantly gas-occupied noncircular pore. J. Colloid Interface Sci. 121, 392-401 (1988).

26. Dong, M. \& Chatzis, I. The imbibition and flow of a wetting liquid along the corners of a square capillary tube. J. Colloid Interface Sci. 172, 278-288 (1995).

27. Romero, L. A. \& Yost, F. G. Flow in an open channel capillary. J. Fluid Mech. 322, 109-129 (1996)

28. Quéré, D. Inertial capillarity. Europhys. Lett. 39, 533-538 (1997).

29. Weislogel, M. M. et al. The capillary flow experiments: handheld fluids experiments for international space station. In 45th AIAA Aerospace Sciences Meeting and Exhibit. Physics of Fluids, 7408-7414 (2004).

30. Weislogel, M. et al. More handheld fluid interface experiments for the international space station (CFE-2) 1-10, https://doi.org/10.2514/6.2009-615 (AIAA, 2009).

31. Weislogel, M. M. \& McCraney, J. The symmetric draining of capillary liquids from containers with interior corners. J. Fluid Mech. 859, 902-920 (2019).

32. McCraney, J., Weislogel, M. \& Steen, P. OpenFOAM simulations of late stage container draining in microgravity. Fluids 5, 207 (2020).

33. Canny, J. A computational approach to edge detection. IEEE Trans. Pattern Anal. Mach. Intell. PAMI-8, 679-698 (1986).

34. Weislogel, M. M., Baker, J. A. \& Jenson, R. M. Quasi-steady capillarity-driven flows in slender containers with interior edges. J. Fluid Mech. 685, 271-305 (2011).

35. Blackmore, W., Weislogel, M., Balasubramaniam, R. \& Kelley, E. Unresolved low-g bubble migration phenomenon: peripheral observations during fluids experiments aboard the ISS. In 50th AIAA Aerospace Sciences Meeting including the New Horizons Forum and Aerospace Exposition 1-11 (AIAA, 2012).

36. Weislogel, M. M. Capillary flow in containers of polygonal section. AIAA J. 39, 2320-2326 (2001).

37. Kistler, S. F. In Wettability (ed. Berg, J.) (Marcel Dekker, 1993).

38. Bostwick, J. B. \& Steen, P. H. Dynamics of sessile drops. Part 1. Inviscid theory. J. Fluid Mech. 760, 5-38 (2014). 
39. Weinstein, S. J., Dussan, E. \& Ungar, L. H. A theoretical study of two-phase flow through a narrow gap with a moving contact line: viscous fingering in a HeleShaw cell. J. Fluid Mech. 221, 53-76 (1990).

40. Bostwick, J. B. \& Steen, P. H. Capillary oscillations of a constrained liquid drop. Phys. Fluids 21, 032108 (2009).

41. de Lazer, A., Langbien, D., Dreyer, M. \& Rath, H. Mean curvature of liquid surfaces in cylindrical containers of arbitrary cross-section. Microgravity Sci. Technol. 9, 208-219 (1996).

42. Finn, R. \& Neel, R. C-singular solutions of the capillary problem. J. Reine Angew. Math. 512, 1-25 (1999).

43. Weislogel, M. M. \& Collicott, S. H. Capillary rewetting of vaned vontainers: spacecraft tank rewetting following thrust resettling. AIAA J. 42, 2551-2561 (2004).

44. Weislogel, M., Jenson, R. \& Bolleddula, D. Capillary driven flows in weakly 3-dimensional polygonal containers. In 45th AIAA Aerospace Sciences Meeting and Exhibit 1-13 (AIAA, 2007)

45. McCraney, J. Single drain data. figshare https://doi.org/10.6084/m9 figshare.16632472.v1 (2021).

\section{ACKNOWLEDGEMENTS}

This work was supported in large part through NASA Grant 80NSSC19K0406. M.W. is supported in part through NASA Grant 80NSSC18K0161. The authors are forever grateful for the creative support of the ISS astronaut crews and cadre-in this case NASA astronauts Michael Hopkins and Rick Mastraccio, and especially JAXA astronaut Koichi Wakata. We dedicate this work and future work like it to the lasting memory of creative and insightful professor and colleague Paul Steen (1952-2020).

\section{AUTHOR CONTRIBUTIONS}

This work was initiated by Ph.D. candidate J.M. and academic advisor P.S. All data reduction and analysis was completed by J.M. with M.W. assisting in data analysis. The writing and editing of the manuscript was split between J.M. and M.W. following the passing of P.S.

\section{COMPETING INTERESTS}

The authors declare no competing interests.

\section{ADDITIONAL INFORMATION}

Supplementary information The online version contains supplementary material available at https://doi.org/10.1038/s41526-021-00173-5.

Correspondence and requests for materials should be addressed to Joshua McCraney.

Reprints and permission information is available at http://www.nature.com/ reprints

Publisher's note Springer Nature remains neutral with regard to jurisdictional claims in published maps and institutional affiliations.

Open Access This article is licensed under a Creative Commons Attribution 4.0 International License, which permits use, sharing, adaptation, distribution and reproduction in any medium or format, as long as you give appropriate credit to the original author(s) and the source, provide a link to the Creative Commons license, and indicate if changes were made. The images or other third party material in this article are included in the article's Creative Commons license, unless indicated otherwise in a credit line to the material. If material is not included in the article's Creative Commons license and your intended use is not permitted by statutory regulation or exceeds the permitted use, you will need to obtain permission directly from the copyright holder. To view a copy of this license, visit http://creativecommons. org/licenses/by/4.0/.

(c) The Author(s) 2021, corrected publication 2021 